\title{
Formação de telespectadores para TVD Interativa apoiada na Sequência Fedathi e Aplicada para o Desenvolvimento de Programas Jornalísticos
}

\author{
Rafaela Ponte Lisboa Cardoso ${ }^{1,2}$, Maria Elizabeth Sucupira Furtado ${ }^{1}$, Hermínio \\ Borges Neto $^{2}$, Camila Silveira ${ }^{1}$ \\ ${ }^{1}$ Laboratório de Estudos do Usuário e da Qualidade de Uso de Sistemas (LUQs) \\ - Universidade de Fortaleza (UNIFOR) - Fortaleza - CE - Brasil \\ ${ }^{2}$ Laboratório de Pesquisa Multimeios - Universidade Federal do Ceará (UFC) \\ Fortaleza - CE - Brasil \\ \{rafaela, herminio\}@multimeios.ufc.br, \{rafaelaplc,elizabet\}@unifor.br, \\ jornal.camila@hotmail.com
}

\begin{abstract}
This paper presents a methodology for the development of educational programs for the Digital Television (DTV) Brazilian, but specifically journalistic. Consists of recommendations for the production of content and based on the viewer focus on training for the possibilities of interactivity available on TVD, the methodology was applied in the pilot of a news program that addresses issues of everyday life among them, the traffic. Preliminary results showed that the methodology is presented properly to explore the potential use in the context of TVD and that it goes through the simple act of producing the content.
\end{abstract}

Resumo. Este artigo descreve uma metodologia pedagógica para o desenvolvimento de programas destinados à Televisão Digital (TVD) brasileira, mas especificamente jornalísticos. Composta de recomendações para a produção dos conteúdos e tendo como base o foco no telespectador em formação para as possibilidades de interatividade disponíveis na TVD, a metodologia foi aplicada no projeto piloto de um programa jornalístico que aborda temas do cotidiano dentre eles, o trânsito. Resultados preliminares mostraram que a metodologia se apresentou adequada para explorar as potencialidades de uso no contexto da TVD e que ela perpassa o simples ato de produção do conteúdo.

\section{Introdução}

A interatividade presente na TVD apresenta-se como um recurso promissor que pode potencializar a educação promovendo a inclusão social, a diversidade cultural do País por meio do acesso à tecnologia digital favorecendo a democratização da informação.

A partir da interatividade vislumbra-se ainda uma mudança de postura do telespectador diante de sua posição no esquema clássico da informação. Ele passa a ser um usuário de aplicativos na TVD, tendo a possibilidade de intervir sobre um conteúdo: enviando mensagem e comentando-o, navegando, modificando-o, etc. Nesta perspectiva, percebe-se a possibilidade de se utilizar a TVD num processo de conscientização e mudança. Todavia, precisa-se repensar o processo de produção de conteúdo para a televisão e, consequentemente, a formação dos profissionais envolvidos nesse processo. Considerando isso, para o desenvolvimento de conteúdo no contexto da TVD, propõe-se, como experiência empírica, uma metodologia baseada na Sequência Fedathi (SF). Na SF, a aprendizagem ocorre via resolução de problemas. Ela vem sendo aplicada para o ensino de outras áreas, como para o ensino de Matemática, Ciências, Informática e para o desenvolvimento de vídeos educativos [Machado et al., 2008] [Lisboa et al., 2011] [Lisboa et al., 2010] [Lisboa et al., 2012] apresentando seu potencial de adaptabilidade. Este artigo apresenta a estensibilidade feita na metodologia SF com relação as suas possibilidades de uso no contexto da TVD. Os aspectos estendidos se referem à: i) Capacidade para auxiliar na formação de telespectadores participativos e; ii) Capacidade para produzir vídeos que motivem o telespectador a ter esta participação, sem necessariamente serem vídeos educativos. 


\section{Contextualização da pesquisa e problematização}

Os pesquisadores deste artigo se depararam com a demanda de um projeto de pesquisa, sendo essa a de desenvolver um programa jornalístico para TVD com a perspectiva de formação de sujeitos/telespectadores. A empresa de tecnologias para mobilidade urbana, com soluções de segurança e gestão de trânsito localizada em Fortaleza-Ceará tinha o interesse em formar telespectadores a absorver de forma clara e objetiva a informação das matérias, transformandoas em conhecimento. Objetiva-se também usufruir da interatividade da TVD a partir do uso de aplicações interativas com informações sobre trânsito (por essa razão o programa abordou o referido tema). Essas necessidades exigem a redução da "complexidade do real para torná-lo inteligível em uma reportagem de TV" [Barbeiro; Lima, 2005, p.102].

A SF é uma metodologia pedagógica que desde sua criação vem sendo estudada e aplicada somente em contextos educacionais. Mas nas experiências anteriores dos autores deste artigo, houve o uso da SF no âmbito educacional para a TVD, dentre elas, no desenvolvimento de conteúdos educativos - os T-VILOS [Lisboa et al., 2010] [Lisboa et al., 2011]. Nestes trabalhos, a utilidade da SF foi comprovada para a formação de telespectadores, mais interativos no contexto de aprendizagem via a TVD. Considerando esta motivação e diante desta nova demanda, começou-se a questionar: Como a SF poderia auxiliar na produção de um conteúdo jornalístico? Várias reflexões surgiram acerca da aplicabilidade da SF. Não estava claro como a SF poderia se estender para esse tipo de gênero. Assim, a fim de torná-la aplicável em vários contextos e apresentá-la enquanto uma proposta para tratar a completude do uso das tecnologias levando em conta seus usuários, os sujeitos. Este trabalho propõe resolver esta lacuna apresentando elementos da SF, que podem fundamentar diversas soluções específicas. Propõe-se um Framework que destaca os principais elementos a serem observados na SF e os pressupostos que norteiam a apreensão e aplicação da SF na elaboração de conteúdos e na formação de profissionais e telespectadores para o contexto de comunicação via a TVD.

\section{Framework}

O Framework da Sequência Fedathi (chamado, FRASF) visa munir os profissionais da área de produção de conteúdos com informações (práticas e categorias), que podem ser aplicadas nos vários contextos de uso da SF. As diversas experiências que utilizaram a SF nortearam os autores deste trabalho a propor a esquematização de uso da SF em vários domínios, indo de um nível mais genérico até a sua especificação, como é mostrado na Figura 1. Passando de um nível a outro, ocorre a instanciação da SF, e é no último nível, que se encontram os conteúdos produzidos a partir das especificações iniciais. O que seria instanciar a SF? Instanciar a SF seria empregá-la em outros contextos, ou seja, adaptar suas práticas e categorias, bem como criar novas em virtude da complexidade e capacidade polissêmica que emerge da dimensão em estudo. A partir deste instanciamento, quem a aplica, pode inová-la e mudá-la constantemente adaptando-a a um novo contexto, traduzindo-a em novos conceitos e perspectivas de uso. O FRASF se apresenta em uma estrutura composta de três níveis distintos: o de metamodelo; o de especificação de cada modelo, na ilustração da Figura 1 identifica-se três modelos; e o de um modelo instanciado. Cada nível pode ser considerado como um nível de abstração diferente. Os conceitos mais gerais sobre SF estão definidos no nível de metamodelo, primeiro nível, no qual se pode ver o sujeito (participativo, critico, criativo), que se orienta (podendo esse ser receptor, aluno, telespectador e/ou emissor, professor, apresentador) e segue práticas (ações/procedimentos que o norteiam na apreensão e/ou na elaboração de conteúdos) e categorias (tecnológicas, pedagógicas e comunicacionais, que apresentam elementos norteadoras no processo de elaboração de um produto, trabalhadas no artigo do SBIE 2011 e WebMedia2012, sendo estas associadas entre si. 


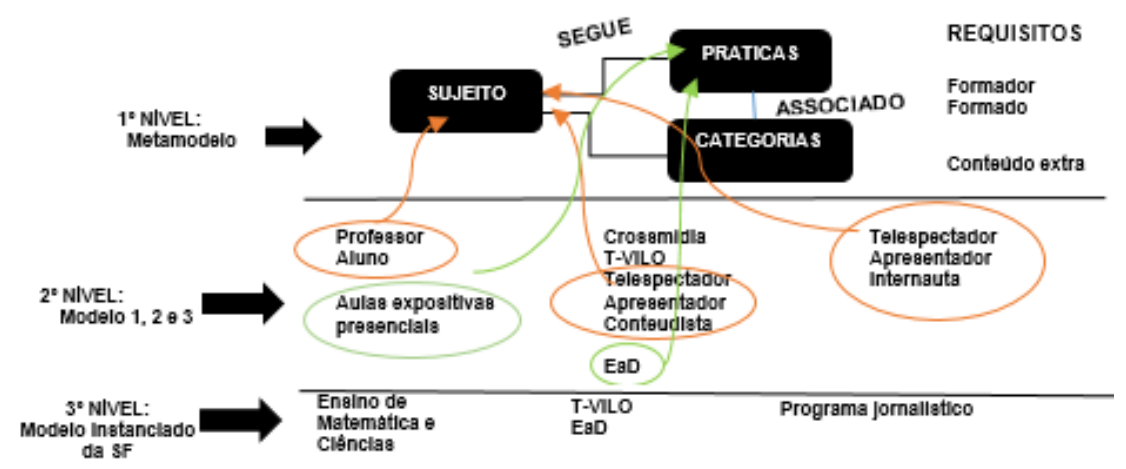

Figura 1 - Modelo de conceitos da Sequência Fedathi em níveis de abstração.

Os conceitos específicos são definidos no nível três, no qual a SF está instanciada. No segundo nível, encontra-se como exemplos para ilustração três usos da SF, o modelo 1 se refere a quando a SF é aplicada para o ensino presencial, o modelo 2 se refere a quando a SF é aplicada para conteúdos educativos para a TVD e o modelo 3, é quando a SF é aplicada para a produção de conteúdo e formação do profissional (foco deste artigo). No terceiro nível, têm-se os conceitos relacionados a uma situação específica. Por exemplo, uma possível instância do modelo 1 representa a forma em que a SF é aplicada em uma situação, que envolve o ensino presencial da matemática, em que um professor apresenta uma problemática durante uma aula para seus alunos. Outra possível instância do modelo 1 representa uma situação de uma aula presencial de ciências. No nível dos modelos, a exemplo do modelo 1, os conceitos sobre o domínio professor-aluno são modelados, enquanto no metamodelo, pode-se fazer a modelagem dos conceitos gerais relacionadas a qualquer domínio de relações, atributos, entidades e assim por diante. O Framework trabalha a SF na perspectiva de propor sua generalização, pois se entende que, por meio de situações genéricas ou generalidades, é possível perceber as principais ideias/informações de determinados conceitos/práticas retratados em sua essência. A seguir destacam-se os pressupostos oriundos dos conceitos gerais traçados no FRASF.

\subsection{Pressupostos}

Tomando como base os conceitos gerais de sujeito, práticas e categorias, tem-se dois pressupostos que auxiliam na proposta de utilização da SF em diversos contextos como uma metodologia e, mais especificamente, para a formação e promoção de sujeitos mais participativos, críticos e criativos. O pressuposto Mediação se refere à relação que ocorre entre os sujeitos envolvidos em um processo de comunicação (emissor x receptor) ou em um processo de aprendizagem (professor $\mathrm{x}$ aluno), que vai depender do foco do conteúdo a ser desenvolvido: uma aula, um vídeo, um texto, etc. Assim, as informações presentes no conteúdo devem ser estruturadas de forma a ajudar o aprendiz a coletar informações, relacioná-las, organizá-las, manipulá-las, discuti-las e debatê-las com seus pares (interaprendizagem), até chegar a produzir um conhecimento que seja significativo para ele, conhecimento que se incorpore ao seu mundo, ou seja, ao seu contexto. Com esse conhecimento, ele pode compreender sua realidade e/ou interferir nela (MORAN, MASETTO, BEHRENS, 2000). O pressuposto sujeito se designa o indivíduo, sendo por fim um indivíduo crítico e consciente dos condicionamentos culturais e econômicos impostos ao sujeito num contexto caracterizado por acentuadas disparidades sociais (FARIAS, 2001). Sujeito que está em uma relação entre sujeitos em uma espécie de interação, há trocas de informações e entendimentos, possibilitando o seu desenvolvimento como um sujeito social/socializado. Diante dessa perspectiva de sujeito deve-se levar em conta suas características, necessidades e perfil, na hora de produzir e estruturar um conteúdo.

\section{Aplicação da SF no Programa Ação na Cidade}

A aplicação da SF na experiência que será apresentada a seguir, deve ajudar a mostrar que a definição dos pressupostos ajuda a: a) construir um conteúdo; b) mostrar como o profissional de jornalismo acaba por refletir sobre suas práticas, enquanto produtor de conteúdo e; c) perceber como é um profissional de jornalismo pode aplicar uma metodologia pedagógica. A seguir aponta-se as extensões feitas em cada fase da SF para o desenvolvimento do programa 
televisivo "Ação na Cidade" para TVD, demanda do projeto já mencionado, e com o foco na formação do telespectador participativo.

\subsection{Programa Ação na Cidade}

O programa Ação na Cidade é um programa piloto desenvolvido pelo Laboratório de pesquisa em Interação Humano computador (http://luqs.unifor.br/luqs/) de uma Instituição de pesquisa, do qual faz parte os pesquisadores deste trabalho, em parcerias com a Emissora da mesma entidade e com a Empresa que demandou o programa. Ele consiste em mostrar os problemas que estão acontecendo na cidade de Fortaleza, onde, como e quem pode ajudar a resolvê-los. O diferencial é a participação do telespectador por meio do controle remoto no qual é dada a oportunidade do público interagir com as informações noticiadas dentro do programa. No projeto piloto, o tema escolhido foi o trânsito da cidade de Fortaleza, assunto de interesse social. Para o desenvolvimento do roteiro do programa, a equipe de pesquisadores convidou uma aluna do curso de jornalismo da Instituição, cursando a disciplina de Princípios e técnicas de telejornal II. Durante a formação, foi exposto para a aluna a metodologia seus pressupostos, bem como acesso à conteúdos produzidos a partir da SF.

\subsection{Estrutura do Conteúdo gerado e a SF Estendida para o Programa}

O programa foi desenvolvido em dois dias e tem uma duração de 6 minutos. O programa tem uma apresentadora e é composto de três blocos, os quais foram planejados de acordo com as fases da SF [Lisboa et al., 2010]. No primeiro bloco ocorre a apresentação do problema, fase de tomada de posição: O que é o TRANSFOR? (Um programa de transporte urbano de Fortaleza que vem realizando várias obras na malha viária da cidade). A apresentadora do programa começa a levantar questionamentos a fim de apreender as possíveis deficiências /dificuldades dos telespectadores em relação aos conhecimentos anteriores que deveriam possuir acerca do assunto. Há o estabelecimento de algumas regras /orientações que nortearão sua relação com o telespectador, que devem ir desde as realizações desejadas frente ao problema proposto, como também, em relação ao tipo de relações permitidas entre os telespectadores. No Segundo bloco (fase de maturação ou debruçamento da SF) ocorre a preocupação com a compreensão e identificação das variáveis envolvidas no problema apresentado no início do programa. Assim, inicia-se uma discussão entre o apresentador e os telespectadores a respeito do problema em questão; o apresentador precisa promover situações em que os telespectadores busquem interagir com ele/programa e apresentar suas opiniões acerca do que foi explorado no referido programa acessando as aplicações interativas para a TVD. No terceiro bloco ocorre a representação e organização de esquemas/modelos que visem à solução do problema. Nesta fase, os telespectadores deverão organizar as informações apresentadas pela apresentadora acerca do assunto. É importante que durante a realização dessa fase, haja a trocas de ideias, opiniões e discussões dos possíveis pontos de vista dos telespectadores, sendo apresentada para eles a fala de vários cidadãos sobre o assunto. Deve-se discutir sobre as colocações apresentadas e fazer um fechamento, uma espécie de conclusão agregando a fala dos cidadãos (da população) e de especialistas (fase da solução/prova da SF).

\section{Resultados}

A seguir faz-se uma breve descrição dos resultados analisados, trazendo duas situações. Na primeira, a análise é feita sobre o programa (roteiro e edição do material capturado nas gravações) desenvolvido, especificamente, sobre os personagens que compuseram o vídeo produzido. Na segunda, a análise é feita sobre a percepção dos produtores do programa diante do uso dos pressupostos, que foram trabalhados em uma oficina de 6 horas, salienta-se na análise a fala de um produtor.

a) Recepção do profissional: Na primeira parte do programa, na fase de tomada de posição da SF, foi possível perceber que a apresentadora usou uma linguagem simples e direta como se estivesse conversando com o público: falando sobre o assunto do programa e explicando as possibilidades da interatividade a partir do uso do controle remoto. Em um segundo momento houve o emprego da fase de maturação da SF: exposição dos questionamentos centrais do tema do programa, apresentação de apontamentos para a percepção do telespectador sobre o tema e 
as possíveis soluções para o problema exposto no início do programa. Foram feitas entrevistas no formato o "povo fala", cujo repórter foi as ruas para ouvir a população, que seria a forma de ouvir quem está em casa para falar um pouco mais sobre o assunto discutido. Em seguida, o repórter foi em busca de uma resposta para esclarecer as dúvidas da sociedade a respeito do assunto. $\mathrm{O}$ repórter entrevistou um especialista no assunto que procurou esclarecer as possíveis dúvidas de quem estava em casa. Por fim, na fase de solução, existiu a preocupação em ter pequenos momentos de reflexão por meio da linguagem em terceira pessoa, como no caso: "VOCÊ JÁ TINHA PARADO PARA PENSAR NISSO?". Desta forma, os produtores do programa esperavam que o público tivesse a sensação que também faria parte do programa e sua participação seria essencial para a produção do programa.

b) Implicação dos pressupostos: No que se refere ao desenvolvimento do programa piloto Ação na Cidade, o produtor (aluna de jornalismo) frisou que incorporar os pressupostos à prática de produção de conteúdo para a televisão, mudou sua perspectiva de produção e conteúdo. De acordo com a profissional "a partir da SF, pode-se estruturar a matéria pensando nos telespectadores, em sua apreensão acerca do assunto". Ela destaca que a preocupação está voltada em atender a necessidade do público, informando-o em todas as instâncias, seja visualizando o problema por meio de recursos tecnológicos ou participando da reflexão e compreendendo a mensagem dita. Além disso, destacou que "o maior aprendizado foi a tentativa de produzir um conteúdo voltado ao público de forma clara e objetiva e que ao mesmo tempo possibilitasse a interação com o assunto noticiado e a reflexão sobre os fatos a sua volta".

\section{Considerações finais}

A partir do emprego da Sequência Fedathi no desenvolvimento de um programa jornalístico, foram realizadas adaptações, adequações na metodologia que resultaram na definição de pressupostos e na versão estendida da SF para esse tipo de gênero televisivo, que passarão a auxiliar os desenvolvedores e produtores a produzirem recursos audiovisuais. Essa metodologia pedagógica aqui apresentada servirá tanto para nortear profissionais que atuam na televisão no desenvolvimento e análise de conteúdos para a TVD, como levar profissionais de educação a conhecerem as possíveis formas de interação com os materiais educacionais e de integração desses materiais com a programação de TV. Este conhecimento tende a contribuir com a evolução de conceitos e metodologias pedagógicas, favorecendo o alinhamento entre a teoria e prática no contexto digital.

\section{Referências bibliográficas}

BARBEIRO, H.; LIMA, P. R. de. Manual de telejornalismo: os segredos da notícia na TV. 2. ed. Rio de Janeiro: Elseiver, 2005.

FARIAS, M. O telensino no cenário nacional e local das políticas de educação a distância. In: FARIAS, I.; NUNES, J.; CAVALCANTE, M. Telensino: percursos e polêmicas. Fortaleza: Edições Demócrito Rocha, UECE, 2001.

LISBOA, R. P.; MENDES, M.; FURTADO, E.; GUSSI, A.; BORGES NETO, H. Requisitos para Elaboração e Integração de Conteúdos com Recursos da TV Digital Brasileira aplicados em Experiências de Aprendizado. In: Anais do XXI SBIE, 2010.

LISBOA, R. P.; FURTADO, E.; GUSSI, A.; BORGES NETO, H. Categorias Comunicacionais para Produção de Conteúdos Educativos para TVD. Anais do XXII SBIE, 2011.

LISBOA, R. P.; FURTADO, M. E. S.; BORGES NETO, H. Verification of crossmedia content for interactive digital television. Proceedings of the 18th Brazilian symposium on Multimedia and the web. WebMedia2012. [doi $>10.1145 / 2382636.2382686]$

MACHADO, A. F. V.; MENEZES, R. M.; REIS, H. T.; RODRIGUES, E. M.; RUZZA, M. Um processo de desenvolvimento e aplicação de desenhos animados educativos apoiado na Sequência Fedathi. Anais XIX SBIE, 2008.

MORAN, J. M.; MASETTO; BEHRENS, M. Novas tecnologias e mediação pedagógica. Campinas, SP: Papirus, 2000. 